EL CARÁCTER

RELACIONAL DE

\section{LA CREATIVIDAD}

HUMANA

*Alfonso López Quintás

\section{RESUMEN}

El presente artículo explora de forma sistemática los elementos concernientes al proceso y al carácter relacional de la creatividad humana a través de sus diferentes campos, y a la vez explica los vínculos generados entre la obra, el creador y el entorno. Dichos nexos son como medios garantes de la armonía estética en la preservación de la vida, frente al egoísmo y la barbarie. Es por este motivo que se analizan aspectos sobre el carácter relacional de la condición humana y la infinidad de espectros que esta asimila y recrea desde lo más hondo de su raíz por cuanto es "un ser de encuentro". El artículo enfatiza la necesidad de fundar una unidad entre el hombre y su entorno, unidad que es básica para una auténtica cultura. La obra de arte y toda creación humana deben ex-

\footnotetext{
* Doctor en filosofía y catedrático de la Universidad Complutense de Madrid. Entre sus numerosas obras estan: $\mathrm{Me}$ todología de lo suprasensible, El conocimiento de los valores, y La cultura y el sentido de la vida.
}

presar relación y proporción, y en ese sentido manifestarán y anunciarán el triunfo de la vida.

\section{INTRODUCCIÓN}

A los siete años de terminar la Segunda Guerra Mundial visité Alemania por primera vez. Al bajar del tren en Colonia, pude ver la inmensa mole de la catedral gótica presidiendo, como una vieja dama enlutada, un mundo en ruinas. Y pensé cómo se explica que la Europa de la gran cultura se haya desgarrado tan ferozmente a sí misma. Ésa era la Europa de Bach y Beethoven, de Miguel Ángel y Rafael. ¿No se había dicho siempre que la cultura eleva nuestro espíritu, nos forma, nos hace crecer como personas?

Ante un espectáculo semejante, producido por la primera hecatombe mundial, un genial maestro de escuela austríaco, Ferdinand Ebner, nos hizo ver, en 1921, que la causa del desmoronamiento de la culta Europa había sido convertir la "vida cultural" en un mero "soñar con el espíritu". ${ }^{1}$ La verdadera cultura implica creación de víncu-

1. Cf. Das Wort ist der Weg (La palabra es el camino), Herder, Viena 1949, pp. 87, 211; Das Wort und die geistigen Realitäten, Herder, Viena 1952, pp. 31, 148, 253, 258-259. (Versión española: La palabra y las realidades espirituales, Caparrós, Madrid 1993, pp. 31, 122, 203, 207. 


\section{ESPIGA}

los, fundación de unidad entre el hombre y su entorno. Soñar con el espíritu es poner en juego nuestras potencias espirituales para conseguir dos metas muy atractivas: realizar experiencias conmovedoras por su belleza y acrecentar el conocimiento a fin de adquirir un inmenso poderío sobre la realidad. Pero todo ello sin comprometer nuestra persona con la de los demás. En su obra clave: La palabra y las realidades espirituales -origen y fuente de buena parte de la Antropología filosófica contemporánea-, Ebner destacó que la vida espiritual auténtica comienza cuando se pronuncia la palabra recta, y esta palabra es la que pronuncia el amor y sirve de vehículo al encuentro humano en todos los órdenes. ${ }^{2}$

Debemos recordar que la cultura es esencial a la vida del hombre, porque éste no vive empastado en el entorno, ya que a cada estímulo puede dar diversas respuestas. Ese distanciamiento le permite y le exige crear con las realidades del entorno diversos modos de unidad y de relación. Todo el universo se asienta en relaciones y vive, por tanto, en unidad.

2. Cf. Das Wort und die geistigen Realitäten, p. 151; La palabra y las realidades espirituales, p. 125.
Sólo el ser humano debe, además de mantenerse en unidad con el entorno, crear modos nuevos de unidad. Esa actividad creadora es el origen de la cultura auténtica. Si nos damos cuenta de todo ésto y sacamos las consecuencias pertinentes - pensaba Ebner-, suscitaremos una "revolución cultural" tan fecunda que dará lugar a una nueva forma de Humanismo, capaz de superar los mayores conflictos. ${ }^{3}$

\section{La importancia decisiva de la categoría de relación}

Vale la pena estudiar a fondo esta sugerencia de Ebner. Lo decisivo en la cultura no es producir obras de arte, de literatura, de ingeniería o de alta filosofía que nos permitan vivir experiencias de impresionante belleza o de adentramiento en el secreto de la realidad. Lo decisivo es crear formas de relación valiosas, por la razón básica de que el ser humano es "un ser de encuentro", según la Biología actual más cualificada. Por eso los biólogos recomiendan actualmente a las madres que, a no ser en caso de enfermedad, amamanten a sus hijos, ya que amamantar no es sólo dar alimento; es acoger. Lo que más necesitan los bebés es verse acogidos

3. Cf. Das Wort ist der Weg, pp. 138-141. 
por el entorno, sentirse inmersos en una trama de relaciones amistosas.

Si por naturaleza somos seres de encuentro y vivimos como personas, nos desarrollamos y perfeccionamos creando toda suerte de encuentros, no es extraño que todas las áreas de conocimiento subrayen la importancia de la categoría de relación.

1. Las Matemáticas tienen como meta primordial la creación de estructuras, y toda estructura implica la ordenación de diversos elementos. Esta forma de orden, configurado por la mente humana, presenta una afinidad enigmática con el orden o interrelación que rige en el universo entero y puede expresarse en fórmulas matemáticas. Los grandes pioneros de la ciencia, Kepler por ejemplo, se extenuaron buscando las fórmulas que permiten pensar racionalmente la constitución íntima del universo por la convicción de que éste se halla ordenado, y toda nuestra tarea investigadora consiste en descubrir ese orden. De ahí que eminentes físicos actuales -Max Planck y Werner Heisenberg entre otros- no tuvieran reparo en afirmar que no es posible hacer ciencia sin el res- paldo último de la creencia en un supremo ordenador del cosmos.

El profesor de Matemáticas debe enseñar a los alumnos a operar con las estructuras matemáticas: fórmulas, ecuaciones, operadores... Es parte esencial de su programa docente. Si a través de tal enseñanza procura que los jóvenes se hagan una idea clara del poder de las estructuras matemáticas, de su belleza -debido a la armonía de los elementos que conjuga- y de la afinidad entre el orden establecido por la mente y el orden que ensambla las diferentes realidades del universo, desde lo infinitivamente pequeño a lo inmensamente grande, pone las bases de una sólida formación espiritual de los alumnos. Estos salen del curso de Matemáticas preguntándose asombrados qué enigmática energía poseen las relaciones.

2. Este asombro se acrecienta cuando, en clase de Ciencias físicas matemáticas, se le descubre que el elemento último del universo no viene dado por formas infinitamente pequeñas de materia sino por "energías estructuradas", es decir, interrelacionadas. "La materia -escribe el físico atómico 
canadiense Henri Prat- no es más que energía "dotada de forma", informada; es energía que adquirió una estructura". ${ }^{4}$ La importancia decisiva de la relación en la constitución última del universo inspiró esta frase al eminente físico inglés A. S. Eddington: "Dadme un mundo -un mundo con relaciones- y crearé materia y movimiento". ${ }^{5}$ El alumno termina el curso de Física descubriendo que la relación está lejos de ser un mero accidente, como se dice usualmente; afecta a los seres en el núcleo mismo de su ser.

3. Este descubrimiento se afirma en su espíritu cuando aprende, en Historia del Arte, que la maravilla del arte griego surgió al descubrir que la belleza es debida a la armonía, y ésta se logra conjuntando la proporción y la medida. Subes a la Acrópolis ateniense y ves cómo se alza al fondo el Partenón. Te asombra su equilibrio y el halo de majestad que irradia. Luego adviertes que esa armonía responde a la proporción precisa que hay entre sus distintas partes y a la adecua-

4. $\quad C f$. L'univers multidimensionnel, Les Presses de l'université de Montreal, Montreal 1971, p. 15.

5. Cf. Space, time and gravitation, Cambridge 1920, p. 202. ción de toda la obra a la figura humana. El encanto de esta obra maestra se debe, en definitiva, a la relación. El radio de la base de sus columnas era tomado como módulo para medir la altura de éstas. Al ser dóricas, debían medir 16 módulos. Si fueran jónicas, 18; si fueran corintias, 20. La anchura del triglifo era tomada como la unidad. La metopa adyacente debía medir 1,6. Hasta los pormenores más exiguos habían de guardar proporción entre sí, y todos con la figura humana. Esta medida o mesura de la obra entera resalta al observar que el Partenón no es ni demasiado grande ni demasiado pequeño respecto a la figura de un hombre normal.

Algo semejante cabe decir de las obras esculturales, por ejemplo la Venus de Milo o el Apolo del Belvedere. Sus dimensiones guardan relación con las de la figura humana, son medidas o mesuradas por ésta. Pero también las dimensiones de cada una de sus partes tienen una medida interior, porque están proporcionadas entre sí conforme a un canon generador de belleza, el célebre canon denominado "sección aúrea" o "número de oro". Los artistas griegos advirtieron que, si se divide una 
superficie en dos partes, de la cual una ocupe el 0,382 del conjunto y la otra el $0,618-\mathrm{O}$ bien, el 0,528 y el 0,472- el efecto resultante es de gran equilibrio y belleza. Las proporciones de la Venus fueron calculadas de esta forma. Se dividió su figura en dos partes: desde la coronilla de la cabeza hasta el ombligo, y desde aquí hasta la planta del pie. Esta segunda parte abarca el 0,618 de la longitud total. La otra se reduce al 0,382. Cada una de estas dimensiones es subdividida en otras dos: desde la coronilla de la cabeza hasta el arranque del cuello, y desde aquí hasta el ombligo. La primera abarca el 0,472, y la segunda el 0,528. Cada una vuelve a dividirse, de forma que hasta la parte más diminuta del cuerpo queda sometida a proporción mutua.

Esta relación proporcional no se ve pero se siente. Es una realidad de tipo distinto a la del material de que está compuesta la obra, pero no es menos real. Es tan real que merced a ella esos productos del ingenio humano se convierten en campos expresivos llenos de armonía. Estas obras pesan, ocupan un lugar, tienen límites precisos, ofrecen resistencia, pueden ser tocadas, desplaza- das, vendidas..., como sucede con los objetos. Pero ellas superan con mucho el nivel de los meros objetos. Son puntos de irradiación de belleza, expresividad y simbolismo. $\mathrm{Y}$ todo ello debido a esa forma privilegiada de interrelación que es la armonía.

Este criterio de la belleza fue aplicado por los griegos a todas las vertientes de la vida humana: la urbanística, la política, la moral... Una acción moral, por ejemplo, es bella si es equilibrada, mesurada, armónica. Una ciudad es bella si sus partes están proporcionadas entre sí y el conjunto está construido a escala humana.

El alumno termina el curso sobrecogido por el poder que tiene la relación de "engendrar obras en la belleza" -como decía Platón- y convertir la vida humana en algo digno de ser amado.

4. Lo dicho acerca de la importancia de la relación halla en la música una confirmación inmediata, vivaz e impresionante. Doy cuatro golpes inconexos sobre la mesa... Todavía no existe el fenómeno musical. Pero vinculo esos golpes entre sí, es decir, los interrelaciono, $\mathrm{y}$ ya tenemos el ritmo, que consta de sonidos ordenados 


\section{ESPIGA}

en el tiempo. Con el ritmo nace la música. Merced a la interrelación rítmica de varios sonidos surge la melodía. Diversas melodías superpuestas dan origen al encantador fenómeno de la armonía. El orden, la interrelación es el origen del edificio impresionante de la música. La sonata en fa menor de Beethoven, la genial Appassionata, comienza con tres notas descendentes: do, $l a, b, f a$. Es una relación, una forma de estructurar los sonidos. De ahí arranca la estructura entera de esa magna obra. Al oír ese tema nuclear, vibramos ya con la obra entera, es decir: entramos en relación creativa con ella.

De forma semejante, al entrar en contacto con los materiales sonoros de una obra, presentimos los otros seis modos de realidad que la integran: los sonidos intervinculados, la estructura que los ensambla, los ámbitos que expresan, el mundo cultural que inspiró su estilo, la emotividad que todo ello suscita, el entorno vital para el que fue compuesta la obra. Al captar la interna vinculación de esos siete aspectos de la obra, es cuando vivimos la experiencia musical en su plenitud estética.

La música nos insta a no quedarnos en los valores inmedia- tos sino a trascenderlos hacia todo aquello a lo que remiten. Aprendemos de esta forma a dotar nuestra inteligencia con las tres condiciones de la madurez: largo alcance, comprehensión y profundidad.

5. Cuando un alumno así formado en las diferentes áreas del conocimiento asiste luego a la clase de Ética -o Formación Humana- y oye explicar al profesor que somos "seres de encuentro" y nuestro verdadero ideal es el de la unidad, exclama, espontáneamente en su interior: "iPues claro! ¿Cómo iba a ser de otro modo si todo el universo está fundado en la relación y nuestras obras culturales más excelsas son tramas de relaciones?"

\section{El privilegio del hombre es crear nuevas formas de relación}

Por estar inserto en el tejido de relaciones que constituyen el universo, el ser humano se halla, desde antes de nacer, ensamblado en tramas de vínculos de todo orden, a los que ha de ser fiel durante la vida. Pero su gran privilegio es poder y deber crear nuevos tipos de relaciones $y$ de unidad con toda suerte de realidades. Por eso, si quiere hacer justicia a su naturaleza más honda, ha de poner gran empeño en descubrir 
qué modos de relación puede crear y qué grados de calidad puede dar a los tipos de unidad que tales relaciones generan. Aquí empieza la apasionante labor formativa, en la cual las diversas formas de experiencia estética pueden prestarnos una ayuda decisiva.

Para hacernos cargo de los modos valiosísimos de unión que podemos crear con los seres del entorno, hagamos la experiencia de aprender de memoria un poema que nos sea desconocido. ${ }^{6}$ Memorizar algo no se reduce a almacenarlo en el interior, sino a meterlo en el corazón, como sugieren los franceses al hablar de savoir par coeur, saber de corazón. "Recordar" es volver a pasar por el corazón (en latín, cor). Por eso decía Unamuno que "recordar es vivir", vivir incluso a veces con más intensidad que nunca. Aprendamos el poema, retirémonos a nuestra habitación y, con el debido recogimiento, recitémoslo con intención creativa, es decir, con la voluntad de darle vida, de poner al descubierto todas las posibilidades expresivas que alberga.

6. La misma experiencia puede realizarse con una canción o una obra instrumental.
“Nuestras vidas son los ríos que van a dar en la mar, que es el morir; allí van los señoríos, derechos a se acabar y consumir (...)".

Cambia el ritmo, fíjate más y más en la eses silbantes y las erres deslizantes; subraya un tanto -más con la intención que con la intensidad de la voz- el valor de los versos más cortos ("que es el morir"; "y consumir")... Al cabo de unos minutos te darás cuenta de que este fragmento de poema ha dejado de serte distante, externo, extraño y ajeno, como era al principio, para hacérsete íntimo, aun siendo distinto. Tú no eres el poema, pero lo has convertido en tu voz interior, en el impulso de tu actividad como intérprete. Cuando lo estás declamando de esa forma re-creadora, el poema es lo más íntimo de tu interioridad.

Ahora dime qué tipo de unidad has creado con el poema, con el autor, con el estilo del autor, con su época... Es una unidad entrañable, intensísima, inimaginable en el $n i-$ vel 1, el de los meros objetos. A un objeto puedo agarrarme con intensidad de náufrago. Levanto las manos y no queda nada. La unión fue intensa pero pobre. En el nivel 1, la unión, por fuerte que sea, es 
siempre tangencial, superficial, pasajera, de tal forma que la realidad a la que nos unimos permanece fuera de nosotros. En el nivel 2 -el del encuentro entre realidades que no son meros objetos sino ámbitos, fuentes de posibilidades- pueden crearse formas de unidad en las cuales se supera la escisión entre el dentro y el fuera, el interior y el exterior, lo privadamente mío y lo crispadamente tuyo. Mis problemas son tus problemas, mis gozos son tus gozos. ¿Nos damos cuenta de lo que significa que una realidad distinta de mí y en principio distante y ajena, pueda llegar a serme íntima sin dejar de ser distinta? Al ser creativos, porque recibimos activamente las posibilidades que nos ofrece una realidad, la convertimos en íntima sin fusionarnos con ella, antes respetando su independencia y fomentando incluso su propia identidad. Estamos, con ello, en un nivel superior de realidad y de conducta -nivel 2-, un nivel que nos abre inmensas posibilidades creativas y nos permite resolver los graves malentendidos que se originan cuando planteamos las actividades personales en un nivel de realidad y de conducta inferior al que les corresponde.

No procede, por tanto, tener miedo a quedarnos solos por no poder superar la distancia entre nosotros y lo que nos es exterior. Si no la superamos es porque no somos creativos, no somos "responsables", no respondemos a la llamada que nos hacen las realidades del entorno a recibir activamente las posibilidades que nos ofrecen, es decir, los valores que nos otorgan. Si a una persona la tomo como un medio para mis fines, no como una fuente de posibilidades de realización personal, la convierto en algo externo a mí, distante, extraño y ajeno. Me quedo solo frente a ella. Pero ello es debido a mi actitud egoísta, no al hecho de que ella sea una realidad distinta de mí.

Lo mismo sucede con la contraposición entre "inmanencia" y "trascendencia". Se dice que lo inmanente está aquí, donde nosotros nos hallamos, y lo trascendente está allá, fuera de nosotros, y se da por supuesto que el aquí y el allá, lo inmanente y lo trascendente se oponen. "Yo me instalo en la inmanencia -ha dicho alguien con vitola de intelectual-; la trascendencia queda, por definición, fuera de mí". Esta afirmación es exacta en el nivel 1; resulta falsa en el nivel 2, el de las realidades ambitales y la actitud creativa.

Para darnos cuenta de lo maravillosa que es la unión que se crea 
entre nosotros y las realidades que asumimos como impulso de nuestro obrar, reparemos en que al principio no conocíamos el poema, nos era externo y desconocido, pero fuimos adentrándonos en él movidos por la energía que nos facilitaba él mismo. En todo proceso de conocimiento de realidades que nos ofrecen posibilidades para actuar con sentido buscamos algo en virtud de la fuerza que nos comunica eso mismo que vamos buscando. Reparemos en que, cuando declamamos el poema, actuamos por propia iniciativa, pero nos sentimos en cierta medida llevados; nos movemos con libertad interior, pero seguimos fielmente el cauce trazado por la obra. No se trata de una actuación paradójica, sino perfectamente lógica en el nivel 2. La importancia de este descubrimiento resalta cuando advertimos que este proceso sorprendente y fecundo de buscar una realidad en virtud de la fuerza que nos viene de ella, se da de forma semejante en la experiencia estética, en la ética, la metafísica y la religiosa. Es el tercer punto que quería tratar.

\section{La afinidad de las diversas experiencias humanas}

La experiencia

de interpretación musical

Tomo la partitura de una obra desconocida para mí y la pongo sobre el atril del piano. En ese instante, la partitura y el instrumento están cerca de mí. La obra, en cambio, se halla a distancia; es, respecto a mí, algo distinto, distante, externo $\mathrm{y}$ ajeno. Pero, como sé leer los signos de la partitura, la obra me invita a asumir sus posibilidades de juego musical y a entrar con ella en una relación de presencia e intimidad. Yo acepto tal invitación, y empiezo a buscar una realidad que me impulsa a crear con ella un nexo profundo, tan profundo y decisivo que de él depende su existencia plena como obra y la mía como intérprete. Sabemos que en la partitura la obra se halla latente, en estado virtual, como una Bella Durmiente que necesita el beso del Príncipe Azul para cobrar vida. El polo evocador de la obra, el que la trae en cada momento a la existencia, el Príncipe Azul es el intérprete.

Estamos ante una experiencia reversible, de doble dirección: Salgo en busca de la obra, pero lo hago con la energía que me da la obra al ofrecerme posibilidades de volver- 


\section{ESPIGA}

la a crear. Quiero encontrarme con la obra porque de algún modo ya estoy en ella, me hallo instalado en su campo de posibilidades de juego. A través de los signos de la partitura adivino las formas que en ellos se expresan e intento expresarlas en el teclado. Lo hago tanteantemente, sin libertad y firmeza. Poco a poco tales formas cobran cuerpo, adquieren una configuración determinada. Tal configuración se la otorgo yo, pero es de ellas. Sin mí, ellas no serían reales; pero yo no soy dueño de ellas. Mi labor se limita a dejar que mi acción troqueladora de la obra sea modelada por la fuerza configuradora de la obra misma. Es decir, yo configuro la obra dejándome configurar por ella. Es ella la que me dice en cada momento si mi interpretación es justa, si pone ya al descubierto sus virtualidades, o debo todavía perfilarla mejor. El juego mismo de la interpretación es una fuente de luz para proseguir la búsqueda de la verdad plena de la obra. Nadie necesita decirme desde fuera lo que tengo que hacer. Es la obra misma la que me guía. Comienza a dirigir el Cuarto Concierto de Brandenburgo de Bach de forma demasiado rápida. Verás que hacia el compás 183 el pasaje rapidísimo del violín solista se convierte en una mancha sonora inexpresiva. $\mathrm{La}$ obra misma te invita a volver al principio y remansar un tanto el rit- mo. Si lo haces, ese pasaje adquiere un especial mordiente y se torna sumamente expresivo.

Cuando buscas algo por iniciativa propia, pero lo haces iluminado por el valor interno de lo que quieres hallar, has de saber que actúas inspirado. Ni dominas, ni eres dominado. Conviertes una realidad distinta en principio impulsor de tu propia actividad y superas la escisión entre la interioridad y la exterioridad, el dentro y el fuera, el dominar y el ser dominado. Al ser fiel a ese principio, no te alienas o enajenas, no pierdes tu iniciativa personal y te conviertas en una marioneta, gobernada desde fuera; te elevas a lo mejor de ti mismo porque pones en juego la capacidad creativa propia de un ser finito.

En el nivel de la creatividad, nivel 2, nadie domina a nadie; todos se intercambian posibilidades de acción creadora y crean un campo de juego en el que se supera la escisión entre el dentro y el fuera, lo interior y lo exterior. Tal superación permite crear modos de unidad muy superiores a los propios del nivel 1, el de la cercanía física y el contacto tangencial. ${ }^{7}$

7. Una amplia descripción de la experiencia de interpretación musical se halla en mi obra Inteligencia creativa. El descubrimiento personal de los valores, BAC, Madrid 2002, pp. 109-115. 
La experiencia ética de interiorización de un valor

Todavía era muy niño cuando un atardecer me sorprendió mi madre con este encargo: "Toma ese bocadillo y llévaselo al pobre que acaba de llamar a la puerta". Yo me resistí porque era un anciano de barba larga y me daba miedo. Mi madre insistió: "No es un delincuente, sino un necesitado; vete y dáselo". Esta tarea la habían hecho hasta ese día mis hermanos mayores. Lo que mi madre quiso a partir de ese momento fue que yo me acercara al área de irradiación del valor de la piedad. Los valores no sólo existen; se hacen valer, y se orlan con una aureola de prestigio. $\mathrm{Al}$ acercarnos a ellos, nos atraen, sin arrastrarnos. Esperan que tengamos la sensibilidad necesaria para captar su invitación y responder a ella positivamente. Pronto observé que ser bueno con los menesterosos encierra un gran valor y procuré asumirlo como propio. El valor de la piedad siguió siendo distinto de mí, pero dejó de ser distante, externo y extraño para convertirse en principio interno de mi actividad y volverse intimo. El primer conocimiento de tal valor me vino sugerido desde fuera. No importa. Lo decisivo es que un día lo convertí en una voz interior y me sentí tanto más libre interiormente cuanto más fiel fui a sus apelaciones. En el nivel 2, la libertad y la obediencia a normas, cuando éstas son juiciosas y por tanto fecundas para nuestra vida creativa, no sólo no se oponen sino que se enriquecen mutuamente. Actuamos con libertad interior o creativa cuando asumimos activamente posibilidades que nos vienen dadas y nos permiten hacer surgir algo nuevo dotado de sentido y relevancia.

Si convertimos un valor en principio interno de acción, damos cumplimiento a una exigencia íntima y experimentamos un sentimiento de plenitud y seguridad, pues no se trata de reconocer una realidad distinta y ajena y doblegarse ante sus exigencias; lo que queremos es vincular (ob-ligar) todo nuestro ser personal a una realidad que lo lleva a pleno desarrollo. Nunca como en esta "interiorización" de los valores estamos más afirmados en nosotros mismos y más rendidamente vinculados a la realidad. Somos plenamente "autónomos" al ser decididamente "heterónomos". 8

8. Sobre las experiencias éticas pueden verse diversas descripciones en mis obras Cinco grandes tareas de la filosofía actual, Gredos, Madrid 1977, pp.105109; El triángulo hermenéutico. Introducción a una teoría de los ámbitos, Madrid 1971. 


\section{ESPIGA}

La experiencia metafísica de inmersión reflexiva en la realidad

"Al comienzo de la conferencia ¿Qué es metafísica?" -uno de sus escritos programáticos-, Martin Heidegger subraya la importancia que reviste en la actividad metafísica la experiencia personal de $i$ mersión.

“¿Qué es metafísica? La pregunta suscita la esperanza de que se va a hablar acerca de la metafísica. Renunciamos a ello. En su lugar analizamos una determinada cuestión metafísica. De esa forma nos sumergimos, sin duda, inmediatamente dentro de la metafísica misma. Con lo cual le procuramos la única posibilidad adecuada para que se nos ponga ella misma de manifiesto". ${ }^{\prime}$

Al final de la obra se cuida el gran filósofo de advertir que, en rigor, no cabe inmergirse en la metafísica porque, "en cuanto existimos, ya nos hallamos siempre en ella". ${ }^{10}$

9. Cf. Was ist Metaphysik, v. Klostermann, Frankfurt 1955, p. 24. Versión española: ¿Qué es metafísica?, Edic. Alpe, Buenos Aires 1955, pp. 17-18.

10. Cf. Was ist Metaphysik, p. 41; ¿Qué es metafísica?, p. 67.
Para entender bien en qué sentido debe hablarse aquí de "inmersión", conviene no entender este concepto en el nivel 1, como una forma de adentrarse en un elemento físico envolvente, por ejemplo el agua. El agua envuelve a quien se sumerge en ella, pero le sigue siendo externa, ajena, y la inmediatez en que se halla respecto a él es de mera cercanía física. Bien es cierto que el agua ofrece posibilidades de juego al hombre que sabe nadar. Cuando éstas son asumidas por el nadador, éste y el agua fundan un campo de juego común, y su relación mutua supera los esquemas "aquí-alli", "dentro-fuera"... El agua no se halla distante del hombre que se mueve en ella, pero tampoco le es intima. Entre ambos media una relación de operatividad, que hace posible una actividad deportiva pero no afecta al sentido mismo de la vida humana. En cambio, cuando asumimos un valor-estético, ético, religioso...-, la inmediatez que se instaura entre el valor y nosotros es de aceptación y de participación. La participación, en el nivel 2, funda un tipo de unidad estrecha y fecundísima entre el ser que participa y el participado. Por eso el valor, aun siendo una realidad distinta del sujeto que se deja sobrecoger por él, se le hace más íntimo que su propia intimidad, pues nada hay más íntimo al 
hombre que lo que le permite desarrollarse plenamente en cada instante por haber sido tomado como principio interno de actuación.

La experiencia de participación artística que diseñamos en el punto anterior la revive el gran filósofo francés Louis Lavelle en el nivel metafísico. ${ }^{11}$ De modo semejante a como el intérprete se ve impulsado y nutrido espiritualmente por la obra musical en la que participa, Lavelle siente en todo momento que su vida como hombre está siendo sostenida, apoyada y promocionada por el Ser que lo rodea y envuelve a modo de atmósfera nutricia. Este modo nutricio de envolver implica un género de flexibilidad y dinamismo del que carecen las cosas, vistas como seres delimitados, opacos, que se relacionan entre sí de modo externo y superficial. Así como la interpretación musical convierte la obra interpretada en íntima al artista, la participación humana en el Ser consiste en ir intimando con él al hilo de la actuación personal, comprometida, en la creación de ámbitos de realidad, hasta llegar a "interiorizarlo", a convertirlo en principio de vida creadora, propia de un ser personal.

11. Cf. De l'acte, Ed. Montaigne, Paris 1946, pp. 147, 150. Sobre este sugestivo tema puede verse mi obra Cinco grandes tareas de la filosofía actual, Gredos, Madrid 1977, pp. 160-167.
La teoría de la participación subraya a la vez la entrega "heterónoma" del hombre al Ser y la promoción "autónoma" de su propia libertad. El Ser, como fuente última de realidad y de vida, ejerce sobre el hombre un poder de apelación que lo insta a responder libremente, con el fin de realizar su propia vocación. Tenemos de nuevo una experiencia reversible: El hombre se plantea el tema del Ser, elabora tratados de metafísica y se pregunta dramáticamente por qué existe el Ser y no más bien la nada porque desde siempre se halla inmerso en el Ser con un tipo de inmersión activa: está recibiendo posibilidades para vivir y actuar en todos los órdenes y se ve instado a asumirlas activamente con objeto de crear algo valioso y dar sentido a su vida. Se dice profusamente que el hombre es un "ser-en-el-mundo", pero el modo de estar en el mundo no es simplemente pasivo; le lleva a realizar toda suerte de experiencias reversibles, que pueden ser fecundas o destructivas y labran con ello su destino. El Ser es la fuente primaria de participación; el hombre se constituye mediante la participación en el Ser, entendido en toda su riqueza.

En el fondo, es la misma estructura bidireccional que caracteriza la experiencia artística. La obra 


\section{ESPIGA}

musical es fuente de participación para el artista que sea capaz de crearla o al menos de contemplarla; el artista se constituye como tal en cuanto participa de obras que le ofrecen posibilidades creativas. ${ }^{12}$

\section{La experiencia religiosa}

También en la experiencia religiosa buscamos a Dios merced a la energía que nos viene de la realidad buscada. Si nos ponemos en marcha hacia Dios es porque de alguna forma ya estamos en Él y venimos de Él.

"El hombre -escribe Xavier Zubiri- está abierto a las cosas; se encuentra entre ellas y con ellas. Por eso va hacia ellas, bosquejando un mundo de posibilidades de hacer algo con esas cosas. Pero el hombre no se encuentra así con Dios. Dios no es cosa en este sentido. Al estar religado el hombre, no está con Dios, está más bien en Dios.

12. La experiencia de participación estética nos da luz para comprender el difícil pensamiento de Karl Jaspers acerca de la "trascendencia", concepto clave en sus obras de creación filosófica. "Si sólo hubiera trascendencia -escribe-, mi voluntad desaparecería, convirtiéndose en obediencia automática. Si, por el contrario, no hubiera en absoluto trascendencia, mi mera voluntad no podría producirla" (Cf. Philosophie II, Springer, Berlín 1932, p. 199).
Tampoco va hacia Dios, bosquejando algo que hacer con Él, sino que está viniendo desde Dios, 'teniendo que' hacer y hacerse. Por esto, todo ulterior ir hacia Dios es un ser llevado por Él. En la apertura ante las cosas, el hombre se encuentra con las cosas y se pone ante ellas. En la apertura que es la religión, el hombre está puesto en la existencia, implantado en el ser (...). Y puesto en él como viniendo 'desde'. Como dimensión ontológica, la religación patentiza la condición de un ente, el hombre, que no es, ni puede ser entendido en su mismidad sino desde fuera de sí mismo". ${ }^{13}$

En una obra posterior, Zubiri aclaró el sentido de esta experiencia reversible en la cual trasciendo hacia Dios porque Dios me hace trascender.

"Escribía San Agustín que Dios diría al hombre: 'Tú no me hubieras buscado si yo no te hubiera encontrado'. Es verdad. Pero verdad parcial, porque no se trata primariamente de una búsqueda sino de un verdadero acceso, todo lo incoado que se quiera, pero verdadero acceso". ${ }^{14}$

13. Cf. Naturaleza, Historia, Dios, Alianza Editorial, Madrid 1987, p. 433.

14. Cf. El hombre y Dios. Alianza Editorial, Madrid 1984, p. 196. 
Dios se entrega al hombre, y a esa donación responde éste con la entrega.

"La forma plenaria de acceso del hombre a Dios es 'entrega". ${ }^{15}$ "Parodiando a San Agustín pudiéramos pensar que Dios diría al hombre: 'No te me entregarías si yo no te hubiera llevado a mí". (...) A la acción donante de realidad por parte de Dios, responde el hombre con una acción positiva en la cual la persona no es llevada a Dios, sino que la persona acepta desde sí misma este su ser llevada de un modo activo y positivo, a saber, 'va a Dios'. (...) A la donación personal que es la presencia fundante de Dios en las cosas y en el hombre, responde la persona humana con esa forma especial de donación que es la entrega de sí mismo". ${ }^{16}$

San Agustín intuyó que la búsqueda de Dios por parte del hombre no es de carácter lineal, como sucede con la búsqueda de las cosas externas, que se hallan fuera de él. A Dios le buscamos invocándole, es decir, estableciendo con Él una relación de reverencia y acatamiento, pero esta actitud sólo es posible si ya le conocemos y nos hallamos

15. Ibid.

16. Cf. Op. cit., pp. 197-198. vinculados a Él por la fe, suscitada por el testimonio de un apóstol. Esa invocación no la dirigimos a alguien que nos sea exterior y se halle fuera de nosotros.

"Que yo, Señor, te busque invocándote -exclama San Agustín- y te invoque creyendo en ti, pues me has sido ya predicado. Invócate, Señor, mi fe, la fe que tú me diste e inspiraste por la humanidad de tu Hijo y el ministerio de tu predicador". ${ }^{17}$

En el nivel 2 -el de las relaciones personales, creativas- y más aún, en el nivel 3 -el de la vinculación incondicional al bien, la justicia, la belleza...- y en el nivel 4 -el de la religación fundamental al Creador-, todas las experiencias ostentan carácter reversible, de doble dirección. Por eso parecen moverse en forma de "círculo", pero no es un círculo vicioso sino virtuoso. ${ }^{18}$ En éste, el sentido pleno de

17. Cf. Confesiones I, 1.

18. Romano Guardini, extraordinariamente sensible para los valores de la vida espiritual, subrayó en diversos contextos la importancia del pensamiento relacional y circular. Véase, por ejemplo, su breve obra Anfang. Eine Auslegung der ersten fünf Kapitel von Augustins Bekenntnissen, Kösel, Munich, 1953, pp. 22-28. Versión española: Principio. Una interpretación de San Agustín, Sur, Buenos Aires 1963. 
cada realidad se alumbra al verla en relación activa con las demás. En el Misterio de Jesús pascaliano, el Señor le dice al creyente: "Consuélate, tú no me buscarías si no me hubieras encontrado" ${ }^{19} \mathrm{He}$ aquí el "pensamiento circular" que debemos poner en juego para comprender a fondo las experiencias reversibles. ${ }^{20}$

\section{La importancia del pensamiento relacional}

Si el hombre es, en verdad, "un ser de encuentro" y está llamado por su misma condición racional, libre y creativa a desarrollarse creando

19. Cf. Pascal: Pensées N. ${ }^{\circ} 553$, Ed. Garnier, París 1955, p. 212. "Tú no me buscarías si no me poseyeras". Confróntense estas expresiones con los capítulos 18 y 29 del libro $X$ de las Confesiones de San Agustín. Véanse los comentarios de Romano Guardini en Christliches Bewusstsein. Versuche über Pascal, M. Grünewald, Maguncia 41991, p. 213. Versión española: Pascal o el drama de la conciencia cristiana, Emecé, Buenos Aires 1955, pp. 231-236.

20. Sobre la afinidad de la experiencia estética, la ética, la metafísica y la religiosa pueden verse mis obras Cinco grandes tareas de la filosofía actual, pp. 102-109; El triángulo hermenéutico. Introducción a una teoría de los ámbitos, Editora Nacional, Madrid 1971, pp. 501-567; La experiencia estética y su poder formativo, Verbo Divino, Estella 1991, pp. 242-264. toda suerte de interrelaciones -lo que le sitúa en una dimensión superior a todos los seres del universo-, debe considerarse obligado en la raíz más honda de su ser a pensar, sentir y querer de modo relacional. El pensamiento relacional supera por elevación la prepotencia del relativismo subjetivista -según el cual todo depende del sujeto que piensa, siente y quiere- y la pasividad indolente del objetivismo, que reduce el sujeto a un espectador sumiso de la realidad externa. La belleza del Partenón no se halla en el sujeto que la contempla ni en el edificio que lleva ese nombre. Surge entre ambos cuando se produce un acto de auténtica contemplación estética. Asimismo, los valores no se revelan sino a las personas "responsables", es decir, dispuestas a responder positivamente a la invitación que ellos le hacen a asumirlos en su vida. Pero dichas personas no son dueñas de los valores.

La forma de pensar relacional concede al sujeto cognoscente la importancia que compete a la función que ejerce, pero no es subjetivista, pues no olvida la parte que corresponde al objeto de conocimiento -que en estos casos no se reduce a mero objeto-. No se olvida del papel ineludible que desempeña el objeto de conocimiento, pero no es objetivista, por tener en cuenta que 
ese papel lo realiza en cuanto se halla abierto al sujeto -no cerrado, como los objetos-, pronto a colaborar con él y dar lugar a una realidad artística como es, por ejemplo, El Partenón.

Al pensar de modo relacional, ampliamos y profundizamos de forma insospechada nuestra visión del universo y de la vida humana. Pongo en la mano un trozo de pan. Parece que se trata de un mero objeto, por ser una realidad delimitable, asible, situable en un lugar $u$ otro, sometible a un análisis científico, producto de un proceso fabril. Ciertamente, el pan lo elabora el hombre, pero lo hace a base de frutos de la tierra, por ejemplo el trigo. Y el trigo no lo produce nadie; es fruto de una confluencia múltiple de elementos que entran en relación a su debido tiempo: el campesino que recibe de sus mayores unas semillas y las confía a la madre tierra; el agua que sirve de mediadora entre las sales de la tierra y la semilla; el océano que evapora el agua; la lluvia que empapa la tierra; el sol que dora la mies... Al ser fruto de la unión de mil realidades, el trigo y, derivadamente, el pan se cargan de poder simbólico cuando un padre de familia parte el pan, lo reparte y lo comparte con un huésped amigo. Lo mismo puede decirse del vino que escancia en su copa.

El pensamiento relacional perfecciona nuestra inteligencia porque le da largo alcance y supera la miopía intelectual; la hace comprehensiva y evita la unilateralidad; agudiza su capacidad de penetración y la redime de la superficialidad. Al no ser superficial sino profunda y captar el verdadero sentido de cada realidad, este tipo de inteligencia suscita la vibración de toda la persona ante las realidades valiosas. Esa vibración emotiva es un modo elevado de sentimiento, que incentiva la voluntad para colaborar creativamente con las realidades admiradas y crear formas relevantes de unión.

$\mathrm{Al}$ crear estos modos de unidad y llevar la propia personalidad a pleno logro, nos convertimos en portavoces del universo. Cada astro se mantiene en unidad con los demás al recorrer su órbita indefinidamente y da con ello gloria al Creador, pero no lo sabe. Al exhibir sus bellas formas y exhalar su perfume, como expresión de su unión a la planta y de la vinculación ecológica de ésta al entorno, la flor da gloria al Creador pero no lo sabe ni lo quiere. Quien lo sabe y debe quererlo es el ser humano. 


\section{ESPIGA}

Cuando una joven, el día de la boda, lleva en sus brazos un ramo de flores, no lo hace sólo porque sean bellas, sino porque quiere darles voz. "Vosotras dais gloria a Dios pero no lo sabéis -viene a decirles-. Venid conmigo, que voy a crear con mi novio una forma eminente de unidad, y en ella tomaréis parte todas las criaturas que os mantenéis unidas y sostenéis el universo".

Al coronar lúcida y voluntariamente esa inmensa y gloriosa pirámide de relaciones que es el universo y convertirse en sus portavoces, los novios alcanzan su máxima dignidad, se ponen en verdad, celebran la gran fiesta del amor, que es la manifestación más brillante de la unidad. Por eso una boda desborda alegría, ya que -en palabras del gran pensador francés Henry Bergson- "la alegría anuncia siempre que la vida ha triunfado", ${ }^{21}$ y no hay triunfo mayor que vivir con plena conciencia y libertad la vocación a la unidad que nos viene de las raíces últimas de la realidad creada y, en definitiva, del Creador.

21. Cf. L'énergie spirituelle, PUF, París, 1944 , p. 23.

22. Cf. August Brunner: La personne humaine, Bauchesne, París 1947, p. 227.
Si vemos en bloque, con mirada sinóptica, lo que significan las interrelaciones en el universo, y adivinamos luego las posibilidades inagotables que tenemos los hombres de crear modos diversos de unidad con los seres del entorno, podemos concluir gozosamente que la investigación de la grandeza del hombre es apasionante y no ha hecho más que empezar. ${ }^{22}$

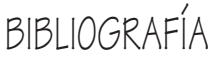

Bergson, Henri, 1944. L'energie spirituelle, París: PUF.

EBNER, Ferdinand, 1949. Das Wort is der Weg, Viena, Ed. Herder.

LÓPEZ Quintás, Alfonso, 2002. Inteligencia creativa. El descubrimiento personal de los valores, Madrid: BAC.

PAscal, 1955, Pensées, París: Ed. Garnier.

PRAT, Henri, 1971. L'univers multimensionnel, Montreal: Les Press de l'université de Montreal.

ZubIRI, Xavier, 1987. Naturaleza, historia y Dios, Madrid: Alianza Editorial. 1984. El hombre y Dios, Madrid: Alianza Editorial. 